\title{
Finite size effect induces stochastic gamma oscillation in inhibitory network with conduction delay
}

\author{
Grégory Dumont ${ }^{1,2,3^{*}}$, Georg Northoff ${ }^{2,3}$, André Longtin ${ }^{1,3}$ \\ From The Twenty Third Annual Computational Neuroscience Meeting: CNS*2014 \\ Québec City, Canada. 26-31 July 2014
}

Cortical gamma frequency $(30-100 \mathrm{~Hz})$ are known to be associated with many cognitive processes. Understanding the dynamics in the gamma band is crucial in neuroscience. Stochastic gamma oscillations due to finite size effects were reported using the stochastic Wilson-Cowan model ([1] and [2]). On the other hand, temporal correlation can be induced by excitation [3] as well as inhibition [4]. Especially, oscillations induced by the conduction delay of the inhibitory feedback is a possible mechanism ([4], [5] and [6]) for gamma rhythms. We investigate the role of both finite size effects and the conduction delay on the emergence of gamma oscillations in an inhibitory allto-all neural network. To this end, we expand the recently proposed linear noise approximation (LNA) technique to this non-markovian "delay" case [1]. This allows us to compute a theoretical expression for the power spectrum of the population activity. Our analytical result is in good agreement with the power spectrum obtained via numerical simulations for a range of parameters.
We show in the left part of the Figure 1 a raster plot depicting the spiking time of each neuron where each neuron follows the stochastic random walk between active and silent state, in red the spike timing of one particular neuron. The second plot is a comparison between the deterministic rate model (black curve) and the stochastic spiking process (blue curve). If the deterministic counterpart reaches a stable fixed point, the stochastic process exhibits self sustained oscillations. In the third plot, the theoretical power spectrum obtained via the LNA method (black curve) and the power spectrum obtained from the numerical simulations (blue curve) are shown to agree nicely. In the last plot we give the phase diagram, showing that the model is under the oscillatory regime. This tells us that gamma oscillations can be caused by the combination of delay and finite size effects in such an inhibitory neural network.
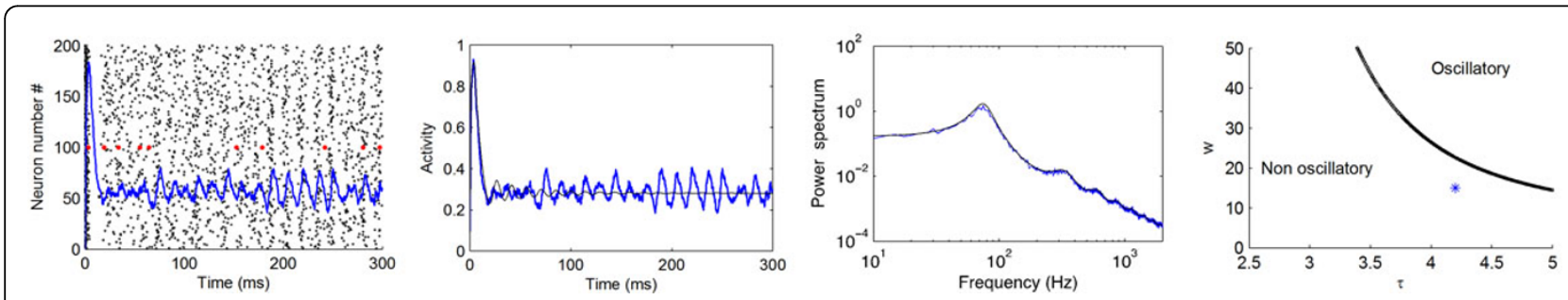

Figure 1 The left panel is a raster plot of 200 interneurons. The blue line represents the global activity of the network. The second panel shows a comparison between the stochastic process and its deterministic counterpart. The third panel compares the numerical (blue) and theoretical (black) power spectra. The last panel shows the phase diagram as a function of the feedback weight and the delay.

\footnotetext{
* Correspondence: gdumont@uottawa.ca

'Physics department, University of Ottawa, Canada

Full list of author information is available at the end of the article
} 


\section{Authors' details}

${ }^{1}$ Physics department, University of Ottawa, Canada. ${ }^{2}$ Mind, Brain Imaging and Neuroethics, Royal Ottawa Healthcare, Institute of Mental Health Research,

Ottawa, Canada. ${ }^{3}$ Center for Neural Dynamics, University of Ottawa.

Published: 21 July 2014

\section{References}

1. Wallace E, Benayoun M, van Drongelen W, Cowan JD: Emergent

Oscillations in Networks of Stochastic Spiking Neurons. Plos one 2011, 6(5):e14804

2. Bressloff PC: Metastable states and quasicycles in a stochastic wilsoncowan model of neural population dynamics. Physical Review E 2010, 82(5):051-903.

3. Dumont G, Henry J: Synchronization of an Excitatory Integrate-and-Fire Neural Network. Bulletin of Mathematical Biology 2013, 75(4):629-648.

4. Brunel N, Hakim V: Fast global oscillations in networks of integrate-andfire neurons with low firing rates. Neural Computation 1999, 11(7):1621-1671.

5. Lindner $B$, Doiron $B$, Longtin $A$ : Theory of oscillatory firing induced by spatially correlated noise and delayed inhibitory feedback. Physical Review E 2005, 72(2):061919-33.

6. Buzsàki G, Wang XJ: Mechanisms of Gamma Oscillations. Annual Review of Neuroscience 2012, 35(10):203-225.

doi:10.1186/1471-2202-15-S1-P115

Cite this article as: Dumont et al:: Finite size effect induces stochastic gamma oscillation in inhibitory network with conduction delay. BMC Neuroscience 2014 15(Suppl 1):P115.

\section{Submit your next manuscript to BioMed Central} and take full advantage of:

- Convenient online submission

- Thorough peer review

- No space constraints or color figure charges

- Immediate publication on acceptance

- Inclusion in PubMed, CAS, Scopus and Google Scholar

- Research which is freely available for redistribution

Submit your manuscript at www.biomedcentral.com/submit
C Biomed Central 